\title{
Spatial and Temporal Pattern Analyses of Esca Grapevine Disease in Vineyards in France
}

\author{
S. Li, F. Bonneu, J. Chadoeuf, D. Picart, A. Gégout-Petit, and L. Guérin-Dubrana
}

First and sixth authors: Université de Bordeaux, ISVV, UMR1065 Santé et Agroécologie du Vignoble, Bordeaux Sciences Agro, F-33175 Gradignan, France, and INRA, ISVV, UMR1065, F-33140 Villenave d Ornon, France; second author: Université d'Avignon (Laboratoire de Mathématiques-EA2151), F-84914 Avignon, France; third author: INRA-Statistics, UR1052, F-84914 Avignon, France; fourth author: INRA UMR ISPA, F-33140 Villenave d'Ornon, France; and fifth author: Institut Elie Cartan, Université de Lorraine, F-54506 Vandoeuvre-lès-Nancy, France. Accepted for publication 21 August 2016.

\begin{abstract}
To assess the capacity of esca to spread within vineyards of the Bordeaux region, over 8 years of annual records, containing between 1,200 and 2,300 contiguous Cabernet Sauvignon vines from 15 mature vineyards, were used for spatial statistical analyses. A group of nonparametric tests, based on join count statistics and on permutation methods, was developed to characterize the spatial structure of esca-symptomatic vines in terms of spread in any direction or within-row only. Among vineyards, a large range of spatial patterns, from random to strongly structured, associated with various prevalence rates that increased over time were observed. In four vineyards, the complex

other vineyards, only small clusters of two adjacent symptomatic vines were observed, and they were localized along rows, without enlargement over time, except in one vineyard. An analysis of spatial dependence between previously and newly symptomatic vines within $k$-order neighborhoods ( $k=1$ to 5 ), showed, for 5 of the 15 vineyards, that the newly symptomatic vines were located close to previously infected vines, without a favored orientation or neighbor order. All the results together suggested a limited potential for secondary local spread from neighboring symptomatic vines.
\end{abstract} esca distribution pattern indicated different levels of clustering. By contrast, in
Additional keywords: fungal disease, join count statistics.
Esca, a grapevine trunk disease (GTD), remains poorly understood but causes extensive damage in vineyards worldwide and results in major economic losses (Bertsch et al. 2013; Mugnai et al. 1999). The identification of key factors that drive esca spread remains a major subject of study in an attempt to understand epidemic progress and to deploy tactical and strategic management practices for this disease.

Grapevine esca, also called esca proper, is defined as a complex dieback disease associated with pathogenic fungi that degrade the woody part of the vine and cause discolored foliar symptoms (Mugnai et al. 1999; Surico et al. 2008). Two forms of the disease are described as follows: a chronic form, characterized by the "tiger stripe" appearance of the affected leaves, and an acute form (also called apoplexy), presenting the dieback of one or more shoots, combined with leaf drying (Mugnai et al. 1999; Surico et al. 2008) in midsummer. Esca foliar symptoms, observed more frequently in 12- to 18-year-old adult vines (Fussler et al. 2008), are commonly associated with two vascular pathogenic ascomycetes, Phaeomoniella chlamydospora and Phaeoacremonium spp., growing within the wood and producing specific necroses, such as black punctuations in trunk cross section and pink-brown or dark red-brown areas in the core of the trunk (Mugnai et al. 1999). In European regions, esca is also associated with Fomitiporia mediterranea, which causes white decay (Fischer 2002; Mugnai et al. 1999). Other Ascomycete pathogenic fungi, Eutypa lata, causing the well-known trunk disease Eutypa dieback, and members of Botryosphaeriaceae, may be involved in esca, as they may be isolated from sectorial necroses in vines showing external foliar esca symptoms (Larignon and Dubos 1997; White et al. 2011). Lecomte et al. (2012) showed that foliar symptoms of

Corresponding author: L. Guérin-Dubrana;

E-mail address: lucia.guerin@agro-bordeaux.fr

(c) 2017 The American Phytopathological Society vines showing esca symptoms, overlapped with some of those of black dead arm, a GTD associated with several species of Botryosphaeriaceae (Larignon et al. 2001). The various means of dissemination and/or infection of these fungi make the study of disease spread difficult. For example, the Ascomycetes, P. chlamydospora and Phaeoacremonium spp., which are endophytic fungi, can be transmitted via vegetative propagation. Consequently, infected young plants may represent a primary source of inoculum introduced into the vineyards (Gramaje and Armengol 2011). Over the vine's lifespan, endo-inocula, like pycnidia and conidiphores of $P$. chlamydospora, produced at the vines surface (bark and pruning wounds), are wind dispersed (Larignon and Dubos 2000) or may be transmitted via cutting tools (Agusti-Brisach et al. 2015) and/or insects (Moyo et al. 2014) to the other vines. However, the aerial inoculum of $F$. mediterranea is assumed to come from external sources because this fungus has not been detected in young nursery plants (Gramaje and Armengol 2011).

The emergence and spread of esca results from complex interactions between types and amounts of inocula, and also other factors, such as plant physiology, abiotic environment (climate and soil), and cultural practices (Bertsch et al. 2013; Lecomte et al. 2011; Murolo and Romanazzi 2014). Spatial statistics and spatial mathematical modeling have been used to describe the distribution and spread of esca in vineyard. Several spatial statistical analyses, based on annual data from different vineyards in Europe, revealed that the random distribution of esca prevails in most vineyard situations (Cortesi et al. 2000; Edwards et al. 2001; Redondo et al. 2001; Sofia et al. 2006; Surico et al. 2000), suggesting that the spread of esca within the vineyard is mainly airborne, via external and/or internal sources of inoculum, rather than due to contaminated pruning tools along rows of vines (Surico et al. 2000). However, aggregated patterns of symptoms have been observed in certain vineyard scenarios (Edwards et al. 2001; Pollastro et al. 2009; Surico et al. 2000), leading to the question of whether there is a secondary spread of esca over time. Only two studies, using spatial 
modeling and several years of recorded data, have investigated this question. Stefanini et al. (2000) proposed a parametric statistical model to estimate the probability that a plant expresses esca symptoms given a set of factors such as symptom expression in the previous year and plant expressing symptoms nearby. The authors observed, for one vineyard in Italy, a slight increase in the probability of symptom outbreak when infected vines were present nearby (along the same row of vines). However, they did not explore the effects of a larger neighborhood. More recently, Zanzotto et al. (2013) analyzed 17 years of data from one vineyard surveyed from planting. Using Bayesian spatiotemporal methods, they investigated the secondary spread of esca infection based on different spatial directions (along- or across-rows). Their results showed a higher probability of esca expression over time and greater spread along rows, rather than among adjacent rows.

To our knowledge, apart from the studies of Stefanini et al. (2000) and Zanzotto et al. (2013), which both used mathematical models applied to spatiotemporal data from only one vineyard, there are no other studies evaluating both the spatial distribution and temporal dynamics of esca. Spatial analyses using data recorded over several years should help us to characterize symptomatic vine cluster enlargement over time and to evaluate the spatial relationship between the previously and newly symptomatic vines. The results may lead to an understanding of the involvement of previously symptomatic vines localized in rows, reinforcing the need for specific sanitary measures. More globally, such a study allows us to describe the scale of the disease's spatial structure over time and the statistical dependence among diseased vines to guide future risk factor research. Also, the results should help define the most relevant distance scale for modeling esca spread within a vineyard.

To address these issues, we analyzed the distribution patterns of vines expressing esca and esca spread over 8 years (6 years for one vineyard), using observations of esca symptomatic and nonsymptomatic vines of the same susceptible cultivar, Cabernet Sauvignon, planted during the same period in 15 mature vineyards. Several types of statistical methods are available to measure spatial structure and intensity using binary data in epidemiological domains (Madden et al. 2007). During the last two decades, a range of different spatial statistical methods were applied to esca. For instance, to test the overall aggregation of esca in vineyards, Reisenzein et al. (2000) compared the expected random and observed distributions directly using a $\chi^{2}$ test, while Cortesi et al. (2000) used nearest neighbor methods, which compared the average distances between observed symptomatic vines to the expectations for random distributions. To quantify the spatial pattern, Surico et al. (2000) combined several methods, dispersion index, quadrat method and ordinary runs, to detect the aggregation along the row. The two-dimensional distance class method (Surico et al. 2000) proposed by Gray et al. (1986) was applied to quantitatively describe the disease at each distance class. In our study, another nonparametric method based on join counts (JCs) and permutation tests (Monte Carlo) was used. This general method is well adapted for data exploration because no assumptions and no prior knowledge of the processes of disease spread are needed. Moreover, one can allow different neighbor definitions based on distance in order to identify the aggregation radius and direction (Pethybridge and Madden 2003). The method addresses the following questions using a large dataset comprised of more than a thousand mapped data points, from an irregular lattice. In our cases, by developing tests based on JCs to analyze the spatial dependence over time between esca vines separated by a specific distance, we addressed different epidemiological questions about esca disease.

The objective of our study was to assess the nature of esca spread within commercial vineyards in the Bordeaux regions in a longterm study. Firstly, we aimed to describe how the disease spreads, by addressing the following questions. What is the rate of the temporal progress of the disease and how does it vary among vineyards? Are symptoms of esca disease always randomly distributed in the vineyard or not? How does the structure of the spatial distribution vary over time? Secondly, we investigated the capacity of local spread along the row or in all directions over time, as well as the relative importance of local disease spread from vines that have previously expressed foliar symptoms.

\section{MATERIALS AND METHODS}

Studied vineyards. Fifteen commercial vineyards in the Bordeaux region, belonging to several owners, were used to monitor esca disease for 8 consecutive years, from 2004 to 2011 (except for one vineyard that was monitored for 6 years, from 2006 to 2011) (Table 1). The 15 vineyards were ordered from 1 to 15 , depending on the disease prevalence in 2011 (except for vineyard 13). All of the vineyards were planted between 1985 and 1990 with the cultivar Cabernet Sauvignon (Vitis vinifera L.) and were trained in accordance with the Guyot method. The vines were grafted onto a variety of rootstocks, depending on the particular vineyard. Within plots, the distance between rows varied from 1 to $3.5 \mathrm{~m}$, and the distances between vines within each row from 0.8 to $1.2 \mathrm{~m}$. The number of living vines per vineyard, monitored at the beginning of the observation period, varied from 1,289 to 2,281 . As the vineyard plots did not form a regular lattice, with rows perpendicular to columns, the alignments of the first vine of each row, the position

TABLE 1. Location and characteristics of the 15 surveyed vineyards and their sanitary state in 2004

\begin{tabular}{|c|c|c|c|c|c|c|c|c|c|}
\hline $\begin{array}{l}\text { Vineyard } \\
\text { number }\end{array}$ & Commune & $\begin{array}{c}\text { Planting } \\
\text { year }\end{array}$ & Rootstock & $\begin{array}{l}\text { Inter-vine } \\
\text { (m) }\end{array}$ & $\begin{array}{l}\text { Inter-row } \\
(\mathrm{m})\end{array}$ & $\begin{array}{c}\% \text { esca vine } \\
\text { in } 2004\end{array}$ & $\begin{array}{l}\% \text { dead, missing, } \\
\text { and young plants }\end{array}$ & $\begin{array}{c}\text { Number of vines } \\
\text { used for } \\
\text { permutation }\end{array}$ & $\begin{array}{c}\text { Total vine } \\
\text { numbers } \\
\text { per plot }\end{array}$ \\
\hline 1 & Léognan & 1988 & $101-14$ & 1 & 1.2 & 0.10 & 2.80 & 1,944 & 2,000 \\
\hline 2 & Capitourlan & 1989 & $101-14$ & 1 & 1.8 & 0.23 & 0.23 & 1,286 & 1,289 \\
\hline 3 & St. Emilion & 1989 & $101-14$ & 1.2 & 1.5 & 0.71 & 2.41 & 1,981 & 2,030 \\
\hline 4 & St. Philippe d'Aiguille & 1987 & $101-14$ & 1.2 & 2.2 & 0.42 & 2.85 & 1,433 & 1,475 \\
\hline 5 & St. Emilion & 1989 & $101-14$ & 1.2 & 1.5 & 1.00 & 1.48 & 2,000 & 2,030 \\
\hline 6 & Margaux & 1987 & $101-14$ & 1 & 1.5 & 2.69 & 12.37 & 1,786 & 2,038 \\
\hline 7 & Canéjan & 1988 & - & 1 & 1.4 & 3.36 & 9.30 & 1,814 & 2,000 \\
\hline 8 & Martillac & 1989 & $101-14$ & 1 & 1.4 & 1.53 & 1.80 & 1,964 & 2,000 \\
\hline 9 & Beautiran & 1990 & - & 1 & 1.8 & 2.97 & 5.37 & 1,919 & 2,028 \\
\hline 10 & St. Philippe d'Aiguille & 1985 & $101-14$ & 1.2 & 2.2 & 4.63 & 2.38 & 1,965 & 2,013 \\
\hline 11 & Espiet & 1989 & $\mathrm{SO} 4$ & 1.2 & 3.5 & 4.81 & 13.85 & 1,766 & 2,050 \\
\hline 12 & Margaux & 1987 & 3309 & 1.2 & 1.2 & $7.57^{b}$ & 10.10 & 1,834 & 2,040 \\
\hline 13 & Castres & 1989 & 3309 & 1.2 & 1.4 & 10.88 & 6.93 & 2,123 & 2,281 \\
\hline 14 & Gradignan & 1989 & $3309 \mathrm{C}$ & 0.8 & 1.5 & 9.21 & 2.06 & 1,998 & 2,040 \\
\hline 15 & Galgon & 1987 & 3309 and Paulsen & 1.2 & 2.9 & 11.70 & 2.90 & 1,942 & 2,000 \\
\hline
\end{tabular}

a Young plants: newly planted or before cordon formation.

b Percent esca vine in 2006. 
(x, y coordinates in meters) of each surveyed vine within each plot, was estimated on an orthogonal basis, using both inter-row and inter-vine distances.

Data collection and temporal disease progress. In 2004 (in 2006 for one vineyard), at the end of August, all of the contiguous vines from each of the 15 vineyards were individually surveyed for foliar esca expression. Symptoms of esca included "tiger-stripe" patterns (chronic form), and the wilting of some or all the vine branches (acute form), which we considered progressive symptoms of the two stages of the same disease. Young plants, including newly planted vines and plants prior to forming cordons, and dead or missing plants, were also recorded. From 2005 (or 2007) to 2011, foliar esca symptoms were recorded by individual vine surveys. The prevalence of esca was calculated by dividing the total number of cumulated vines exhibiting esca symptoms since 2004 (or 2006) by the number of living vines, excluded the young plants, counted in 2004 (or 2006). The results were expressed as a percentage. The temporal progress of the esca prevalence from 2004 to 2011 (or 2006 to 2011) was empirically approximated from the linear temporal curves of all of the vineyards, and the coefficient of determination, $R^{2}$, was calculated.

Spatial point pattern analysis based on JC statistics. The spatial patterns of symptomatic vines in each year were analyzed using statistical tests based on JC statistics adapted for binary data (Moran 1948).

Distance tests. A set of statistical tests was designed for a lattice to detect dependence between symptomatic vines separated by a certain distance, regardless of the orientation or location on the same row, respectively, called the omnidirectional distance test and row distance test. For a lattice of grapevines $l$, the spatial locations of vines are $s_{i l}=\left(x_{i l}, y_{i l}\right)$, the coordinates of vine $i$. We denote the status of vine $i$ associated with the spatial unit $s_{i l}$ at time $t$ by $c_{i l t} . c_{i l t}$ is defined by

$$
c_{i l t}=\left\{\begin{array}{c}
1, \text { if vine } i \text { of lattice } l \text { expresses esca symptoms } \\
\text { at or before year } t \\
0, \text { if vine } i \text { of lattice } l \text { didn't express esca symptoms } \\
\text { at year } t \text { or before }
\end{array}\right.
$$

To determine whether esca diseased vines in a pair of sites separated by a certain distance are dependent, the number of symptomatic vine location pairs separated by this distance are counted and compared with the expected number of pairs under the null hypothesis of random distribution.

For each vineyard, the JC statistic is determined, regardless of the orientation or the along-row direction, for each distance class $[r-1, r]$ (greater than $r-1$ and less than or equal to $r$ ), with $r$ varying from 1 or 2 to $15 \mathrm{~m}$, depending on the smallest distance between two vines in the vineyard (Table 1). These consecutive distances cover the range of distances from those between adjacent vines to those corresponding to the vineyard radius.

For the omnidirectional distance test, the JC statistic is defined by

$$
\begin{aligned}
J C \_ \text {distance } & \text { omni }(l, t, r)=\frac{1}{2} \sum_{i \neq j} c_{i l t} c_{j l t} \omega_{l i j}^{\text {omni }}(r) \\
\omega_{l i j}^{\text {omni }}(r) & =1_{\left\{r-1<\left|s_{i l} l^{-} s_{j l}\right| \leq r\right\}}
\end{aligned}
$$

with $\omega_{l i j}^{o m n i}(r)$, a weight with value 1 if the distance between the two plants at sites $s_{i l}$ and $s_{j l}$ belongs to the distance class $[r-1, r]$ and 0 for all other cases. The null hypothesis, $H_{0}$, is that the cases of esca are distributed at random in the lattice, and the alternative hypothesis, $H_{1}$, is that pairs of symptomatic vines belonging to the distance class are significantly more frequent than expected from a random distribution.
A similar JC statistic is computed for the row distance test, JC_distancerow, using a new weight defined by

$$
\omega_{l i j}^{\text {row }}(r) \omega_{l i j}^{\text {row }}(r)=1_{\left\{r-1<\left|s_{i l}-s_{j l}\right| \leq r \text { and } x_{i l}=x_{j l}\right\}}
$$

To provide a direct evaluation of the unilateral right-sided departure of the observed pattern from $H_{0}$, we computed the same JC statistic for the observed data and for 1,000 simulations by fixing the missing, dead and 1-year-old vines, and by reallocating the remaining locations randomly. An approximate $P$ value was computed in corrected form according to Phipson and Smyth (2010).

Neighbor tests. To study the local dependence between newly diseased plants and previously diseased plants, based on the order of neighbors located around or on the same row, two complementary tests called the omnidirectional neighbor test and row neighbor test, respectively, were developed.

For each year $t$, the spatial dependence between previously and newly symptomatic vines situated in a close neighborhood was analyzed by considering the $k$ th neighborhood order, with $k$ varying from 1 to 5 . The term "previously symptomatic" defines vines that had previously expressed esca symptoms before $t$, and "newly symptomatic" defines vines that expressed esca symptoms at $t$ for the first time. To determine $k$ th neighborhood order, regardless of the direction or the row, the nonequal distance between two adjacent rows and between two adjacent vines along the row were taken into account, and an elliptical band, shaped by the distance between vines located along two adjacent rows $\left(\Delta x_{l}\right)$ and the distance between two consecutive vines along the same row $\left(\Delta y_{l}\right)$, is considered (Fig. 1). Two vines at sites $s_{i l}$ and $s_{j l}$ of the same vineyard $l$ are neighbors of order $k$ if their coordinates satisfy

$$
(k-1)^{2}<\frac{\left(x_{i l}-x_{j l}\right)^{2}}{\left(\Delta x_{l}\right)^{2}}+\frac{\left(y_{i l}-y_{j l}\right)^{2}}{\left(\Delta y_{l}\right)^{2}} \leq k^{2}
$$

The JC statistics count the vine pairs, including a newly and a previously symptomatic vine, according to the given definitions,

$$
\begin{gathered}
J C \_n e i g h b o r^{o m n i}(l, t, k)=\frac{1}{2} \sum_{i \neq j}\left(c_{i l t}-c_{i l(t-1)}\right) c_{j l(t-1)} \omega_{l i j}^{o m n i}(k) \\
\omega_{l i j}^{\text {omni }}(k)=1_{\left\{(k-1)^{2}<\frac{\left(x_{i l}-x_{j l}\right)^{2}}{\left(\Delta x_{l}\right)^{2}}+\frac{\left(y_{i l}-y_{j l}\right)^{2}}{\left(\Delta y_{l}\right)^{2}} \leq k^{2}\right\}}
\end{gathered}
$$

$\omega_{l i j}^{o m n i}(k)$ indicates whether vines $i$ and $j$ of lattice $l$ are neighbors of order $k$. The JC statistics for the row neighbor test are defined by changing $\omega_{l i j}(k)$. The number of observed pairs was compared with the expected number of pairs of the same category under the null hypothesis $H_{0}$ (the newly symptomatic vines were randomly distributed among the vines that were asymptomatic at the previous date). The significance test described below was also performed using permutation tests. In the latter case, the field simulations were generated by fixing the previously symptomatic vines in year $t$ (those of $c_{j l(t-1)}=1$ ), as well as the dead, missing and 1-year-old plants, before each permutation.

Thus, to detect a general trend in the spatiotemporal data sets, we built several groups of global tests as suggested in Thébaud et al. (2005). These global tests synthesized the deviations of observed JC statistics from the means of JC statistics computed under $H_{0}$. For the groups of global tests, after testing the global hypothesis, each was performed with Bonferroni corrections (Bland and Altman 1995).

For each vineyard, the aggregation patterns at different scales and different years were analyzed using these individual tests in an exploratory fashion and several significance levels $(0.05,0.01$, and $0.005)$ have been used to present more detailed results.

Global tests. We performed groups of global tests using specifically defined statistics, which summed up the deviations of 
the observed JC statistics from means of permuted deviations computed on JC statistics under the null hypothesis.

Global distance test per vineyard. To detect the spatial nonrandomness in vineyards, a global distance (GD) test was performed for each vineyard using the $H_{0}$ : in the vineyard $l$, the esca cases are distributed randomly and globally in all of the years included. The alternative hypothesis is $H_{1}$ : occurrences of esca for two different vines a distance apart comprised between $r-1$ and $r$ are not independent in the vineyard $l$ at least for 1 year and one distance $r$. The definition of each test is as follows:

$$
\begin{aligned}
J C_{\text {distance }}{ }^{\text {global }}(l)= & \sum_{t=2004}^{2011} \frac{\sum_{r=1}^{15} \mid J C_{-} \text {distance }}{\text { omni }}(l, t, r) \\
& -\overline{J C_{\text {distance sim }}^{\text {ommi }}(l, t, r)} \mid W(l, t, r)
\end{aligned}
$$

A weighted sum of differences between the observed JC statistics and the means of the simulated JC statistics for all of the distance classes, from 1 to $15 \mathrm{~m}$, and in each year from 2004 (or 2006) to 2011. We summed positive values to avoid the negative compensations that may influence the sensibility of the global test.

The weight is defined as the inverse of the averaged simulated JC statistics,

$$
W(l, t, r)=\frac{1}{J C_{\text {distance sim }}^{\text {omni }}(l, t, r)}
$$

to balance the JC statistics from different scales. The JC statistic calculated for larger distance classes or later years will count more in a nonweighted mean. Moreover, because the statistical test is meaningless for the distance class/year that has few pairs, we used 0 for the weights of the distance class/year in which the number of diseased pairs was less than 10 .

With this construction of the global statistic, the global test was bilateral for $H_{1}$ : the esca cases are nonrandomly distributed for all of the years and for all of the distances in the vineyard $l$ (the observed global statistic is significantly different from the statistic under the random distribution).

To determine whether the nonrandomness was at large scales or at small scales, and/or along-row or not, for the vineyards showing significant nonrandomness, we performed a group of tests containing four global tests, two at small scales, global distance small (GDS) tests and two at large scales, global distance large (GDL) tests by summing the differences computed using omnidirectional and row distance JC statistics, respectively, from 1 to $5 \mathrm{~m}$ and from 5 to $15 \mathrm{~m}$, respectively, in the same manner as $J C_{\text {distance }^{g l o b a l}(l) \text {. }}$
$G D$ test per vineyard per year. To further explore the temporal evolution of the esca vines spatial distribution, for each vineyard showing significant nonrandom patterns, a global test was performed for each year with $H_{0}$ : For vineyard $l$ and year $t$, the esca vines are randomly distributed. The definition is as follows:

$$
\begin{aligned}
J C_{\text {distance }^{\text {global }}(l, t)=} & \sum_{r=1}^{15} \mid J C_{-} \text {distance }^{\text {omni }}(l, t, r) \\
& -\overline{J C_{\text {distance sim }}^{\text {omni }}(l, t, r)} \mid W(l, t, r)
\end{aligned}
$$

Global neighbor test per vineyard per order. To determine the neighbor order in which the newly diseased vines are distributed conditionally on the previously diseased vines, groups of global tests containing 10 tests (omnidirectional/neighbor orders) with $H_{0}$ : In the period 2004 to 2011 , for vineyard $l$, the new cases of esca were randomly distributed among asymptomatic vines in each vineyard. Hypothesis $H_{1}$ : For vineyard $l$, the new cases of esca depended on previous cases in neighbors of order $k$ for at least 1 year. The definition is as follows

$$
\begin{aligned}
J C_{\text {neighbor }}{ }^{\text {global }}(l, k)= & \sum_{t=1}^{8} \mid J C_{- \text {neighbor }}^{\text {omini }}(l, t, k) \\
& -\overline{J C_{n e i g h b o r ~ s i m}^{\text {omi }}(l, t, k)} \mid W(l, t, k)
\end{aligned}
$$

The codes to perform these tests were written in $\mathrm{R}$, and the package "Spatstat" was used to generate spatial functions (R Development Core Team 2013).

\section{RESULTS}

Temporal progress of the disease. In 2004, the percentage of esca vine varied between 0.1 and $11.7 \%$, and the percentages of dead, missing, or 1-year-old plants were between 0.23 and $13.85 \%$, without correlation between the variables $\left(R^{2}=0.224\right)$ (Table 1). The temporal esca progression, shown in Figure 2 for the 15 vineyards, greatly differed depending on the vineyard, with disease prevalence varying between 1.34 and $45.3 \%$ at the end of the survey. Among the 15 vineyards, the prevalence in vineyards 1 to 5 remained low, from 1.34 to $5.30 \%$. By contrast, a high prevalence was found in the first year in vineyards 13,14 , and 15, at 10.88, 9.21, and $11.70 \%$, respectively. Their prevalence rates were between 34 and $45.3 \%$. The temporal progress of esca prevalence from 2004 to 2011 (or 2006 to 2011) was empirically approximated from the linear temporal curves of all of the vineyards, with a coefficient of determination, $R^{2}$, between 0.92 and 0.99 (Fig. 2). The rates of

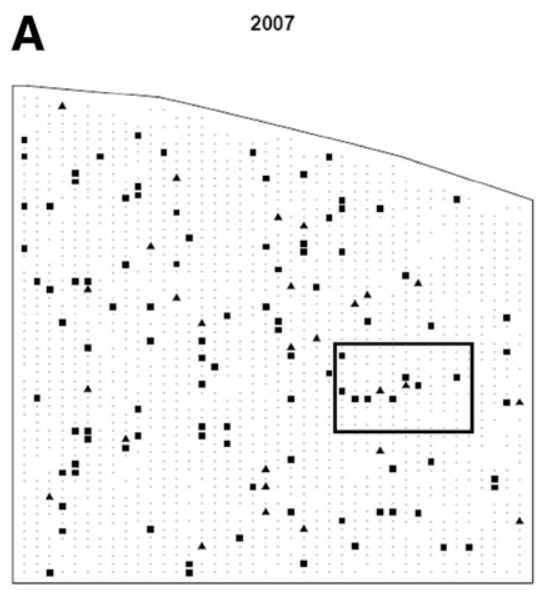

B

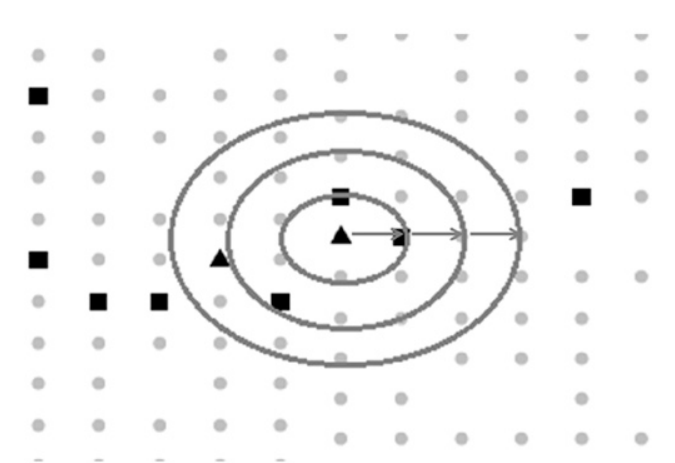

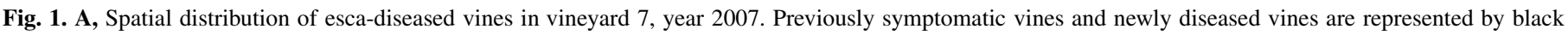

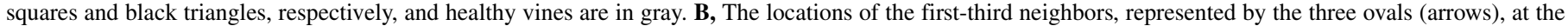
center, and one newly diseased vine (black triangle). 
esca spread among vineyards ranged from 0.18 to $4.94 \%$ prevalence/year. Some of the vineyards, 9, 12, 13, 14, and 15, showed a linear increase in the first year of the survey followed by a slowdown.

Global spatial analyses within vineyards. The GD test per vineyard, using the results of the JC_distance ${ }^{\text {omni }}$, showed that 9 vineyards $(2,4,7,8,9,11,12,13$, and 14$)$ out of the 15 vineyards had significant $P$ values $(<0.0033)$, after Bonferroni corrections, indicating that the esca distribution differed from a random pattern in these vineyards (Table 2). When looking at individual vineyards with significant global tests, we focused on the GD test per year. The year of transition from a random to a nonrandom distribution or, in some cases, conversely, varied according to the vineyard. Only four vineyards (vineyards 7, 8, 12, and 13) showed a nonrandom disease distribution from the first or second year of recordings, indicated by significant values $(P<0.0083$ for vineyard 12 and $P<0.0062$ for the others), after Bonferroni correction, for each year.

Spatial pattern at small and large scales. Table 3 presents the results of the distance tests, to distinguish the statistical dependence between esca vines at small (GDS tests) and large scales (GDL tests), oriented along the row, or not, for each vineyard. For the omnidirectional tests, the vineyards $2,4,7,8,11,12,13$, and 14 showed significant GD tests per vineyard, revealing a significant $P$ value $(P<0.0125)$, at least at a small scale. The four vineyards 7 , 8,12 , and 13 , in addition to vineyard 2 , showed a significant $P$ value $(P<0.0125)$ using omnidirectional GDS and GDL tests, indicating a complex structural pattern. Within four vineyards $(4,11,14$, and

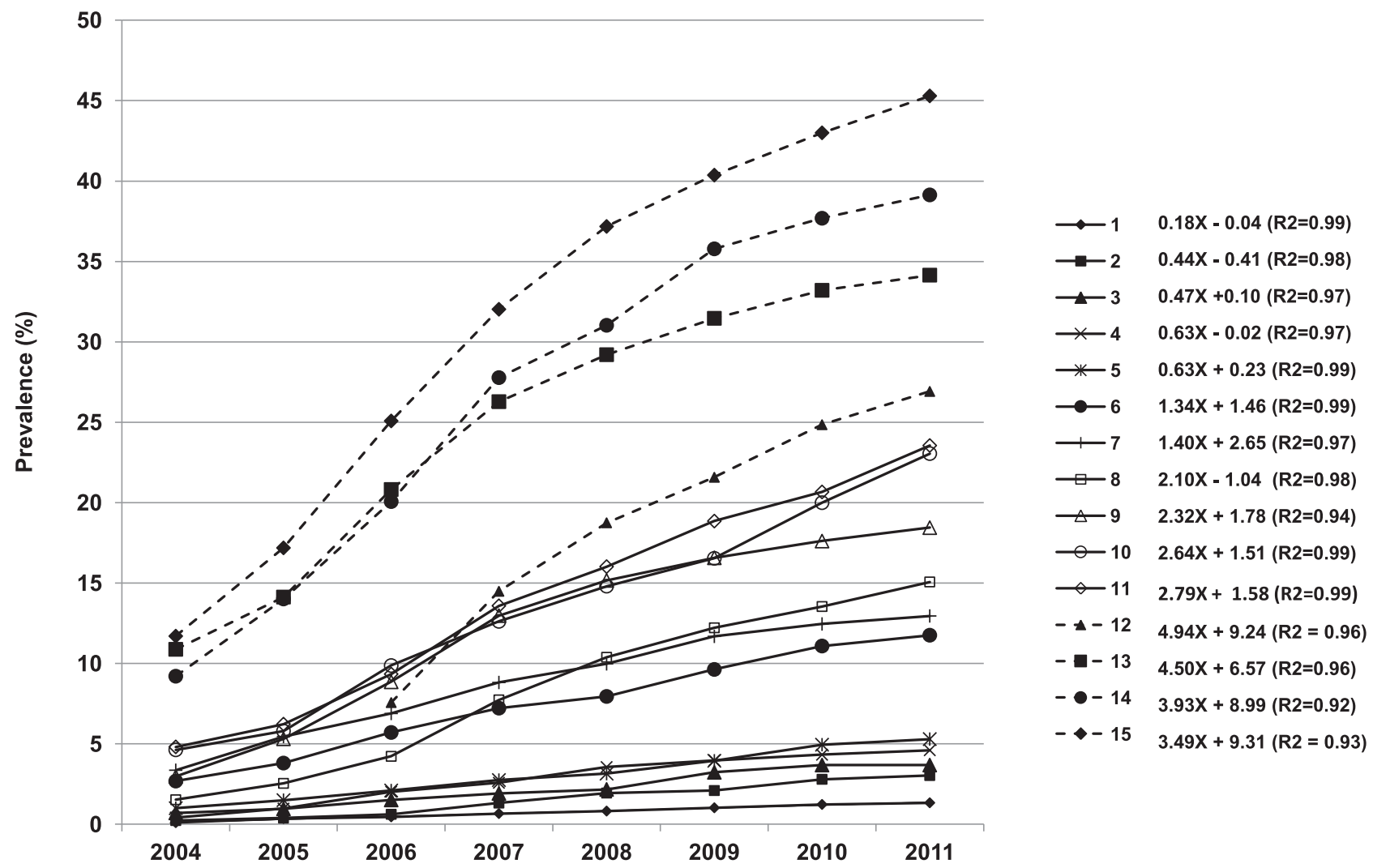

Fig. 2. Yearly prevalence of grapevine esca between 2004 and 2011 for the vineyards 1 to 15 , except for vineyard 13 (from 2006 to 2011 ). Equations of approximated linear temporal curves with determination coefficient $\left(R^{2}\right)$.

TABLE 2. $P$ values of omnidirectional global distance (GD) tests for each vineyard and $P$ values of omnidirectional GD test per year ${ }^{\mathrm{a}}$

\begin{tabular}{|c|c|c|c|c|c|c|c|c|c|}
\hline Vineyard number & GD test & 2004 & 2005 & 2006 & 2007 & 2008 & 2009 & 2010 & 2011 \\
\hline 1 & 0.004 & - & - & - & - & - & - & - & - \\
\hline 2 & $<0.001$ & F & F & F & 0.0410 & 0.0160 & 0.0050 & 0.0020 & $<0.001$ \\
\hline 3 & 0.2168 & - & - & - & - & - & - & - & - \\
\hline 5 & 0.0450 & - & - & - & - & - & - & - & - \\
\hline 6 & 0.0469 & - & - & - & - & - & - & - & - \\
\hline 7 & $<0.001$ & $<0.001$ & $<0.001$ & $<0.001$ & $<0.001$ & $<0.001$ & $<0.001$ & $<0.001$ & $<0.001$ \\
\hline 8 & $<0.001$ & 0.0020 & 0.0040 & $<0.001$ & $<0.001$ & $<0.001$ & $<0.001$ & $<0.001$ & $<0.001$ \\
\hline 11 & $<0.001$ & 0.7423 & $<0.001$ & 0.0040 & $<0.001$ & 0.0160 & 0.0150 & 0.1279 & 0.1978 \\
\hline 12 & $<0.001$ & ND & ND & 0.0020 & $<0.001$ & $<0.001$ & 0.0020 & $<0.001$ & - \\
\hline 13 & $<0.001$ & 0.1488 & 0.0260 & $<0.001$ & 0.0020 & $<0.001$ & $<0.001$ & $<0.001$ & $<0.001$ \\
\hline 14 & $<0.001$ & 0.4446 & 0.1099 & 0.0120 & 0.0170 & 0.0050 & 0.0040 & 0.0110 & 0.0050 \\
\hline 15 & 0.005 & - & - & - & - & - & - & - & - \\
\hline
\end{tabular}

a Significant $P$ values are marked in bold, with the significance level adjusted using a Bonferroni correction performed within each group $(P$ value $=0.05 / 15=$ 0.0033 for the global tests per vineyard, and $P$ value $=0.05 / 8=0.00625$, except for vineyards 1 and $2, P$ value $=0.05 / 5=0.01$, and vineyards 4 and $12, P$ value $=$ $0.05 / 6=0.0083$, per vineyard per year). $\mathrm{F}$, few diseased pairs (not tested); ND, no recorded data; and - , not tested. 
$15)$, esca vines were only significantly aggregated at a small scale because significant $P$ values $(P<0.0125)$ were found only for the GDS tests. The vineyards 5 and 9 with nonsignificant omnidirectional GDS tests had significant GDL test results $(P<0.0125)$. The results of the row GDS tests were similar to those for the omnidirectional tests. Only vineyard 9 had a significant value $(P<0.0125)$ for the row GDS test but not for the omnidirectional GDS test. This indicated the occurrence of symptomatic vine clusters solely oriented along rows in this vineyard. Eight vineyards $(2,3,4,6,7,8$, 11 , and 12$)$ showed significant values $(P<0.0125)$ for the row GDL tests. Vineyard 10 did not show any aggregation pattern.

TABLE 3. $P$ values of the global distance tests for each vineyard summing statistics for all classes of omnidirectional distances (or along row) from 1 to $5 \mathrm{~m}$ (global distance small [GDS] classes) or all classes of omnidirectional distances (or along row) from 5 to $15 \mathrm{~m}$ (global distance large [GDL] classes) ${ }^{\mathrm{a}}$

\begin{tabular}{lcccc}
\hline Vineyard number & Omni GDS & Omni GDL & Row GDS & Row GDL \\
\hline 1 & $\mathrm{~F}$ & $\mathbf{0 . 0 0 4 0}$ & $\mathrm{F}$ & $\mathrm{F}$ \\
2 & $\mathbf{0 . 0 0 6 0}$ & $<\mathbf{0 . 0 0 1}$ & $\mathrm{F}$ & $\mathbf{0 . 0 0 7 0}$ \\
3 & 0.0220 & 0.7153 & 0.0380 & $<\mathbf{0 . 0 0 1}$ \\
4 & $<\mathbf{0 . 0 0 1}$ & 0.4276 & $<\mathbf{0 . 0 0 1}$ & $<\mathbf{0 . 0 0 1}$ \\
5 & 0.7782 & $\mathbf{0 . 0 0 4 0}$ & 0.0170 & 0.2987 \\
6 & 0.3067 & 0.0190 & 0.4046 & $\mathbf{0 . 0 0 2 0}$ \\
7 & $<\mathbf{0 . 0 0 1}$ & $<\mathbf{0 . 0 0 1}$ & $<\mathbf{0 . 0 0 1}$ & $<\mathbf{0 . 0 0 1}$ \\
8 & $<\mathbf{0 . 0 0 1}$ & $<\mathbf{0 . 0 0 1}$ & $\mathbf{< . 0 0 1}$ & $<\mathbf{0 . 0 0 1}$ \\
9 & 0.0300 & $\mathbf{0 . 0 0 6 0}$ & $\mathbf{< 0 . 0 0 1}$ & 0.0899 \\
10 & 0.1698 & 0.4855 & 0.2547 & 0.0969 \\
11 & $<\mathbf{0 . 0 0 1}$ & 0.3846 & $<\mathbf{0 . 0 0 1}$ & $<\mathbf{0 . 0 0 1}$ \\
12 & $<\mathbf{0 . 0 0 1}$ & $<\mathbf{0 . 0 0 1}$ & $<\mathbf{0 . 0 0 1}$ & $<\mathbf{0 . 0 0 1}$ \\
13 & $<\mathbf{0 . 0 0 1}$ & $<\mathbf{0 . 0 0 1}$ & $<\mathbf{0 . 0 0 1}$ & 0.1369 \\
14 & $<\mathbf{0 . 0 0 1}$ & 0.5934 & $<\mathbf{0 . 0 0 1}$ & 0.8901 \\
15 & $\mathbf{0 . 0 0 5 0}$ & 0.1958 & 0.1858 & 0.4126 \\
\hline
\end{tabular}

${ }^{\text {a }}$ Significant $P$ values are marked in bold. The significance level was adjusted using a Bonferroni correction performed on four tests for each vineyard; the significance level was reduced to $0.05 / 4=0.0125$. F, few diseased pairs (not tested).
Spatial pattern over time. Figures 3, 4, and 5 present the evolution of the esca disease pattern over time using statistical test results for each distance class and each year. Nine GD tests in individual vineyards are shown. The vineyards $7,8,12$, and 13 showed a great number of low $P$ values from 2006, 2007, or 2008, revealing a tendency toward spatial dependency $(P<0.005$ or $P<$ 0.01 ) for distances between 1 and $10 \mathrm{~m}$ (Fig. 3). This can be explained by clusters of esca vines at the small scale, distant from each other up to $10 \mathrm{~m}$, as illustrated by the map of vineyard 7 (Fig. 4). Among the vineyards, only vineyard 7 showed a great number of extremely low $P$ values of $<0.005$ for the small distance tests and for the two first recording years. Figure 4 illustrates the results of tests for each distance class, and for 2007 and 2010, the number of pairs of symptomatic vines observed was always greater than those from the simulations. This indicated that the esca vines aggregated at different scales. From 2004 or 2006 to 2008 or 2009, for the vineyards 7, 8, 12, and 13 the number of low $P$ values, and also the maximal distance having a low $P$ value, increased, but without an observed continuum over time (Fig. 3). These results indicated no clear spatial extension of the clusters. Similar results were found with the row distance test (data not shown).

By contrast, the omnidirectional tests, for the other five vineyards (2, 4, 9, 11, and 14$)$, showed that low $P$ values were mostly obtained for the minimum distance class between esca vines, except for vineyard 2 (Figs. 5 and 6). This corresponded to the distance class between two adjacent vines located on the same row, indicating small clusters oriented along rows. Over time, there was no great increase in the number of low $P$ values, except for in vineyard 14. In this vineyard, the increase was associated with an increase in the maximum distance, suggesting an increase in the size of the esca vine cluster over the years. Row test results were consistent with omnidirectional test results. The $P$ values were mainly obtained for minimum distances between two vines, corresponding to the adjacent vines on the row. For vineyards 9 and 14, in 2011 and 2010,
Vineyard 7

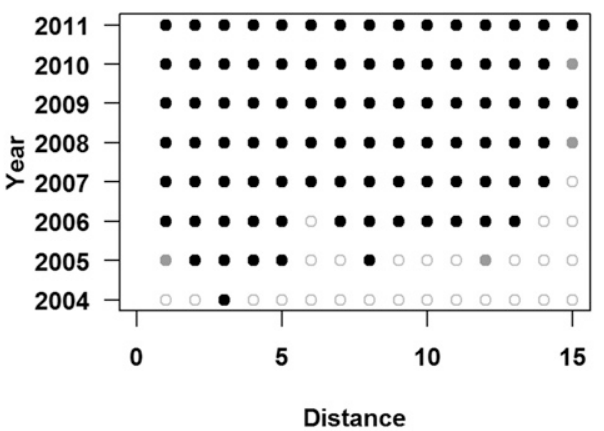

Vineyard 12

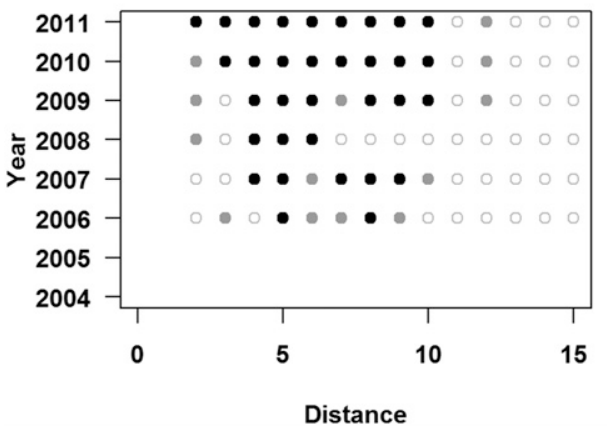

Vineyard 8

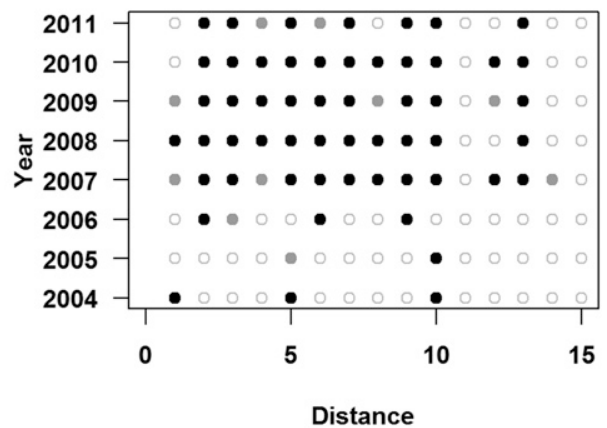

Vineyard 13

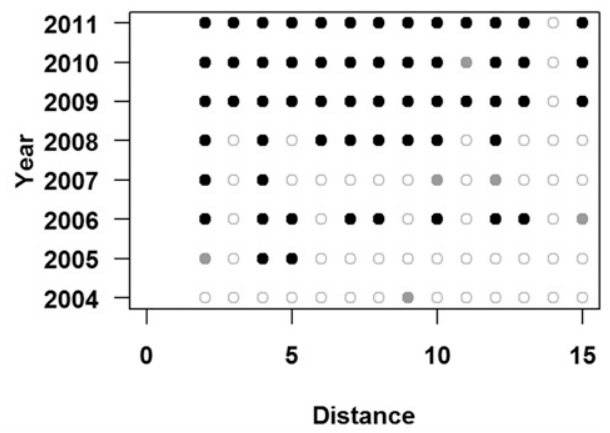

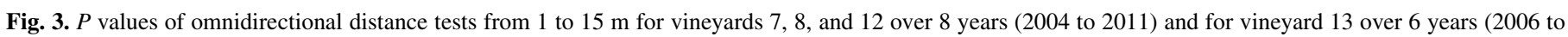

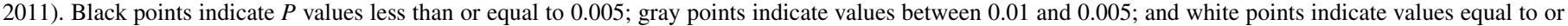
greater than 0.01 , which correspond to the strong, less strong, and no rejection of their null hypotheses (randomness), respectively. 
respectively, an interaction was observed between two vines 2 or $3 \mathrm{~m}$ apart in the row, demonstrating the existence of small symptomatic vine clusters located along the rows that expanded very slowly over the years.

Location of new symptomatic vines near vines with esca. Five $(7,8,12,13$, and 14$)$ of the 15 vineyards showed significant $P$ values with Bonferroni corrections $(<0.0033)$ for one or both global neighbor tests (omnidirectional and row; Table 4). This indicates that for these vineyards, new symptomatic vines were located close to the previously expressed symptomatic vines. When looking at individual vineyards and considering the omnidirectional global neighbor test, a significant effect of neighbors nearby was found, independent of the neighbor order, for the vineyards 7 and 12. For the other three vineyards $(8,13$, and 14), the number of significant $P$ values varied between one and three. For the row neighbor test, only vineyards 7 and 12 showed significant $P$ values without indicating a specific neighbor order.

\section{DISCUSSION}

In this study, spatial pattern analyses of annual data records, over 8 years, of contiguous vines of the same cultivar Cabernet Sauvignon from 15 adult commercial vineyards in the Bordeaux region were conducted to better understand the capacity of esca to spread within a vineyard. The results indicated a large range of disease rate and progress over time among vineyards of similar age.
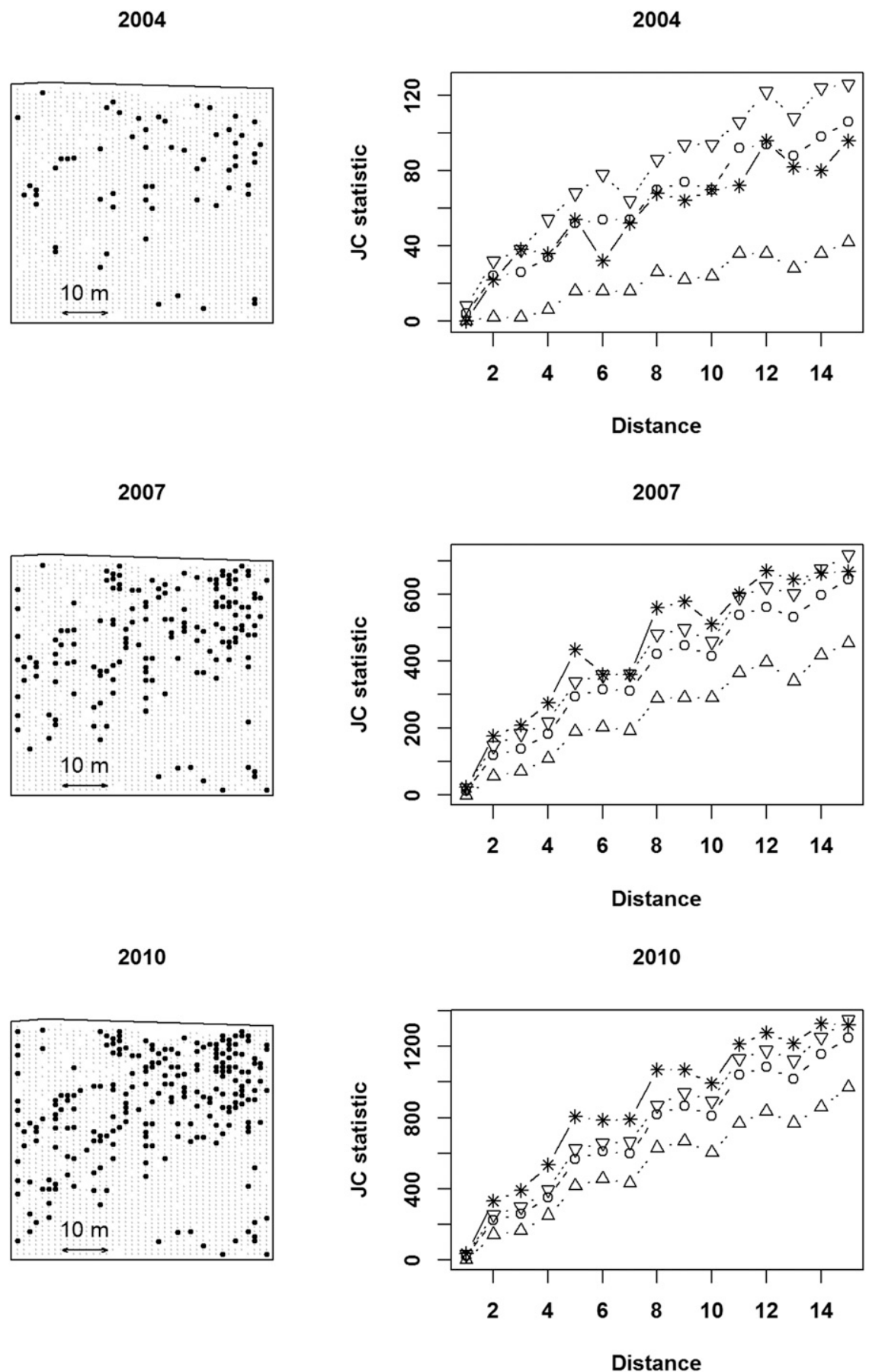

Fig. 4. Distribution of esca-expressing vines and the JC statistics for vineyard 7 in the years 2004, 2007, and 2010. The black curve with stars corresponds to the observed JC statistics at each distance. The dotted and dashed lines with triangles indicate the maximum and the minimum values of the JC statistics, calculated by 1,000 simulations under the null hypothesis. The dotted and dashed line with circles indicates the 95th quantile. If the circle is above the star of the 95th quantile, the test is significant at the 0.05 level without adjustment. 
Various spatial patterns, from random to strongly aggregated structures were observed, with no relationship between spatial pattern and disease rate. For instance, in some vineyards with high prevalence, a random pattern was observed. Enlargement of diseased vine clusters over years was rarely observed (just in one vineyard). About local spread, in 5 of the 15 vineyards, the newly symptomatic vines were located close to previously infected vines, without a favored orientation or neighbor order.

All the results together suggested that there is limited potential for the secondary local spread from neighboring symptomatic vines.

The limited potential for secondary local spread may be explained by the fact that the overall contribution of the short-distance spread, by different means (insects, water splash, and air), did not exceed the contribution of the random long distance spread. We conclude that esca does not generally spread from vines in close contact, and we suggest instead that the new symptomatic vines often occur randomly in the vineyard. The appearance of new cases may be more frequent in areas of the vineyard that are the most conducive to esca, inducing an

Vineyard 2 omnidirect. test

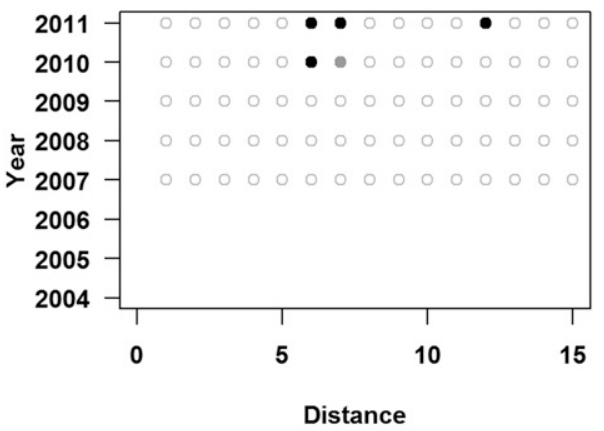

Vineyard 4 omnidirect. test

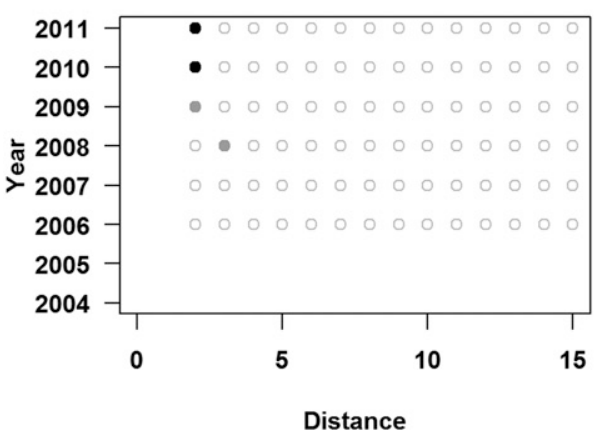

Vineyard 9 omnidirect. test

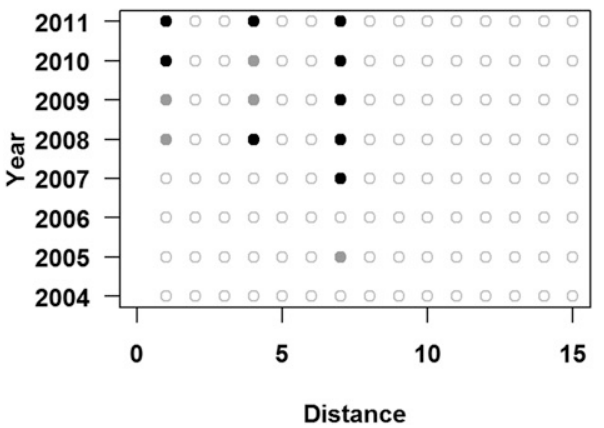

aggregated distribution. This conclusion is reinforced by the lack of a clear relationship between the prevalence level and the spatial pattern of the disease. In some vineyards showing a high prevalence, a random pattern for the disease was observed.

The random or weakly aggregated pattern in most of the vineyards in our study corroborated the results of previous spatial analyses, even though they were conducted in different countries under different agronomic conditions (Cortesi et al. 2000; Edwards et al. 2001; Redondo et al. 2001; Sofia et al. 2006; Surico et al. 2000). The random spread can be explained by the dispersion of pathogenic agents associated to esca. In the Bordeaux region, $P$. chlamydospora, $P$. aleophilum, and F. mediterranea are the main fungi associated with esca disease (Larignon and Dubos 2000). $P$. chlamydospora and $P$. aleophilum are considered aerial fungi (Eskalen and Gubler 2001; Larignon and Dubos 2000). They also may be spread by water splash or insects (Edwards et al. 2001; Mostert et al. 2005). Moyo et al. (2014) showed that arthropod may be potential vectors of GTD and are effective in short-distance
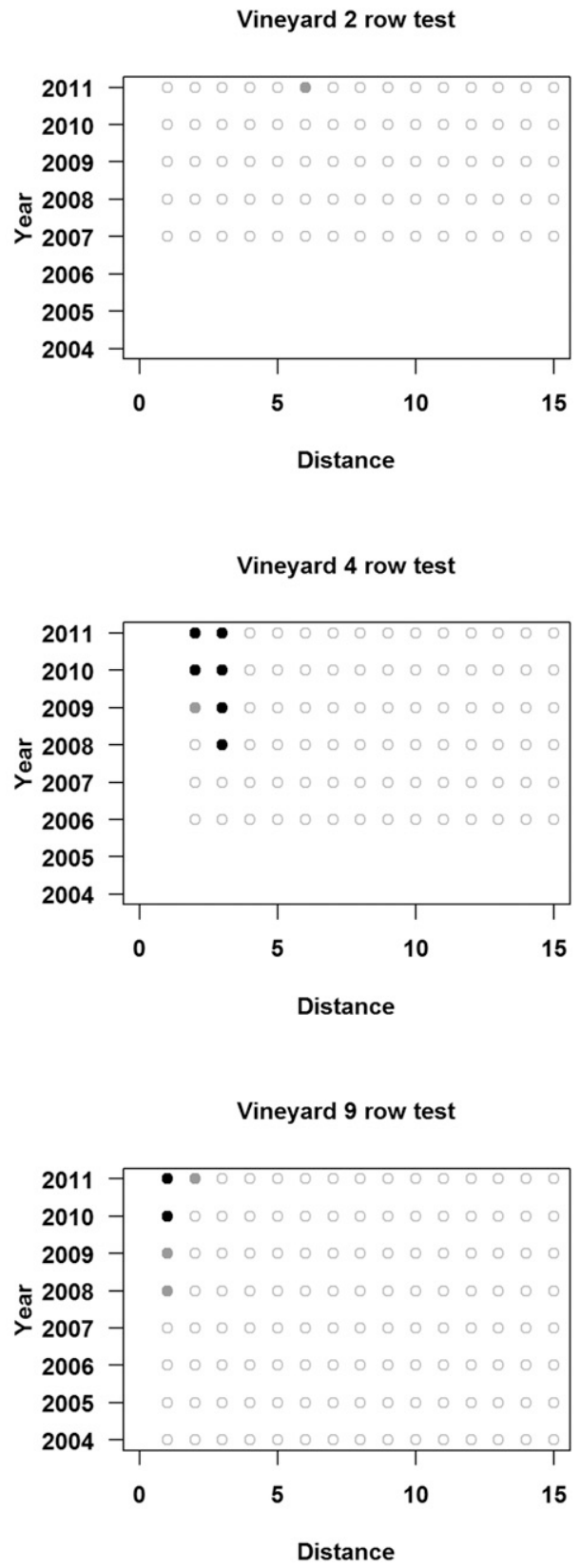

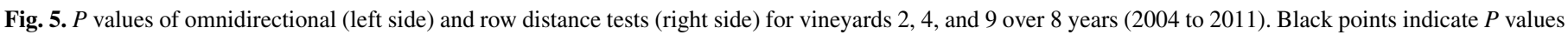

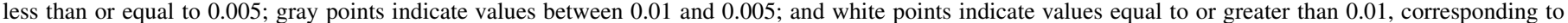
strong, less strong, and no rejection of their null hypotheses, respectively. 
or long-distance pathogen dispersal, depending on the taxon. $F$. mediterranea, associated with decaying wood, is considered a wind-dispersed fungus because of the basidiospores found within or outside vineyards. Consequently, the multiplicity of the dispersal capacity of the fungi involved in esca may explain the absence of typical patterns of spread.

For four of the vineyards surveyed $(7,8,12$, and 13$)$, beginning in the first years of the survey, very low $P$ values were observed for short-distance classes, thereby confirming an aggregation structure.
We could interpret the significance tests for long-distance classes as showing a relationship between two spatially distant diseased vine clusters. The nonrandom spatial pattern within a vineyard can be explained by the spatial heterogeneity of inoculum sources within plots. The pathogenic fungi $P$. chlamydospora and $P$. aleophilum may be present on plant surfaces or inside necrotic or nonnecrotic woody tissues (Bruez et al. 2014; Gramaje and Armengol 2011). When planting, using batches of the most contaminated plants in particular areas of the vineyard may lead to spatial heterogeneity of esca among
Vineyard 11 omnidirect. test

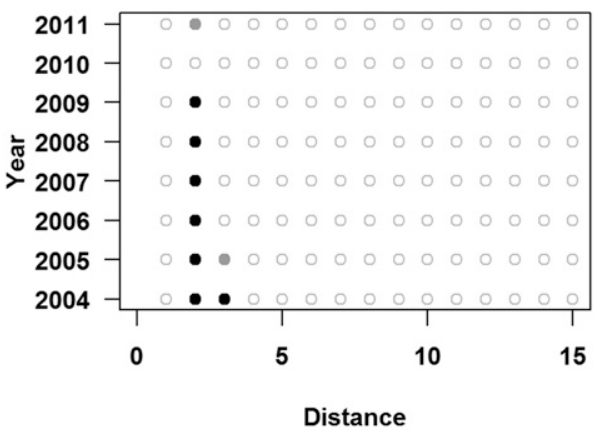

Vineyard 14 omnidirect. test

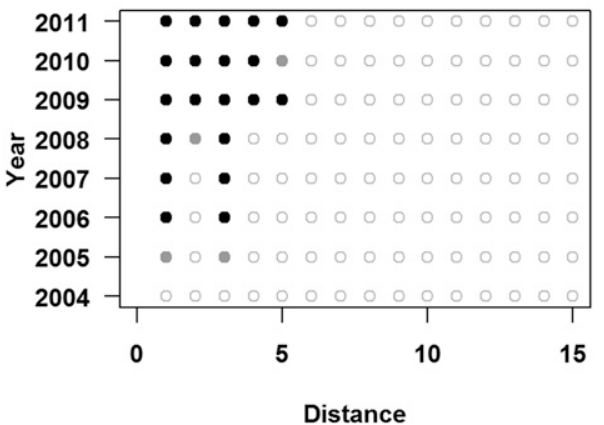

\section{Vineyard 11 row test}

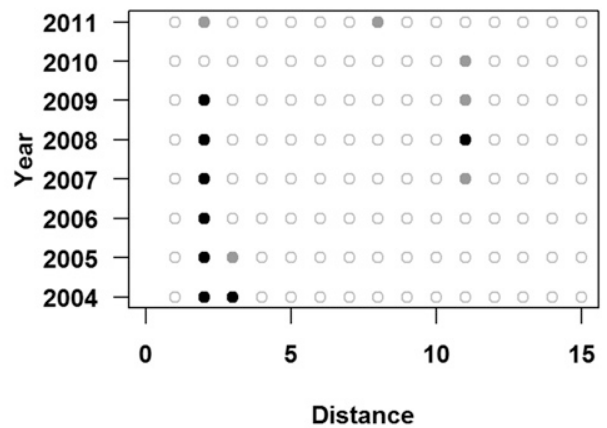

Vineyard 14 row test

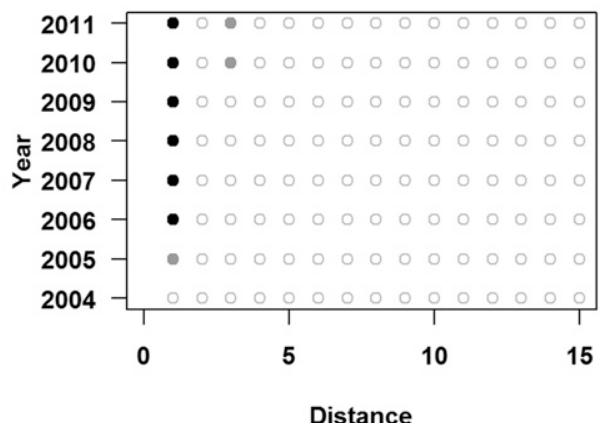

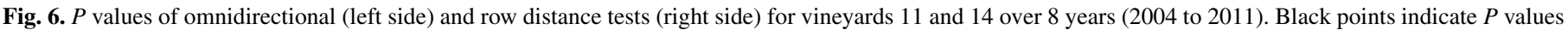

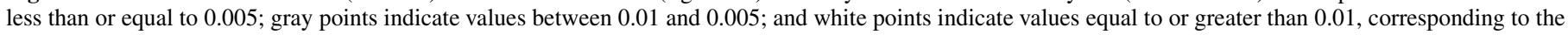
strong, less strong, and no rejection of their null hypotheses, respectively.

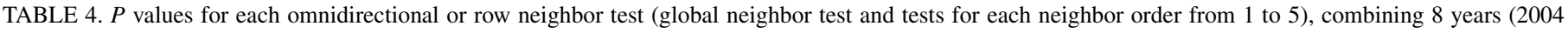
to 2011) of data ${ }^{a}$

\begin{tabular}{|c|c|c|c|c|c|c|c|c|c|c|c|c|}
\hline \multirow{3}{*}{$\begin{array}{l}\text { Vineyard } \\
\text { number }\end{array}$} & \multirow{2}{*}{\multicolumn{2}{|c|}{$\begin{array}{c}\text { Global neighbor } \\
\text { tests }\end{array}$}} & \multicolumn{10}{|c|}{ Neighbor order } \\
\hline & & & \multicolumn{2}{|c|}{1} & \multicolumn{2}{|c|}{2} & \multicolumn{2}{|c|}{3} & \multicolumn{2}{|c|}{4} & \multicolumn{2}{|c|}{5} \\
\hline & Omni & Row & Omni & Row & Omni & Row & Omni & Row & Omni & Row & Omni & Row \\
\hline 1 & 0.3776 & 0.0539 & - & - & - & - & - & - & - & - & - & - \\
\hline 2 & 0.2098 & 0.2318 & - & - & - & - & - & - & - & - & - & - \\
\hline 3 & 0.3916 & 0.7772 & - & - & - & - & - & - & - & - & - & - \\
\hline 4 & 0.1498 & 0.0809 & - & - & - & - & - & - & - & - & - & - \\
\hline 5 & 0.0420 & 0.0220 & - & - & - & - & - & - & - & - & - & - \\
\hline 6 & 0.4655 & 0.6274 & - & - & - & - & - & - & - & - & - & - \\
\hline 7 & $<0.001$ & $<0.001$ & $<0.001$ & 0.004 & 0.001 & 0.1029 & $<0.001$ & $<0.001$ & $<0.001$ & $<0.001$ & $<0.001$ & 0.9650 \\
\hline 8 & $<0.001$ & 0.0200 & 0.0420 & 0.2238 & 0.2218 & 0.2028 & 0.0320 & 0.1099 & 0.1868 & 0.2797 & 0.003 & 0.0200 \\
\hline 9 & 0.0310 & 0.2547 & - & - & - & - & - & - & - & - & - & - \\
\hline 10 & 0.9670 & 0.8182 & - & - & - & - & - & - & - & - & - & - \\
\hline 11 & 0.6473 & 0.6833 & - & - & - & - & - & - & - & - & - & - \\
\hline 12 & $<0.001$ & 0.003 & 0.004 & 0.002 & 0.0100 & $<0.001$ & $<0.001$ & 0.0849 & $<0.001$ & 0.5804 & 0.003 & 0.0689 \\
\hline 13 & $<0.001$ & 0.002 & $<0.001$ & 0.1658 & 0.6104 & 0.0889 & 0.0889 & 0.1109 & 0.0190 & 0.1758 & 0.0539 & 0.0899 \\
\hline 14 & $<0.001$ & 0.002 & $<0.001$ & 0.0250 & 0.1978 & 0.1389 & 0.1389 & 0.1389 & 0.003 & 0.1808 & 0.0879 & 0.8741 \\
\hline 15 & 0.3766 & 0.5724 & - & - & - & - & - & - & - & - & - & - \\
\hline
\end{tabular}

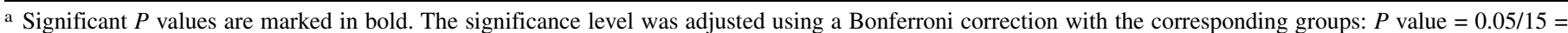
0.0033 for omnidirectional and row global neighbor tests per vineyard, and $P$ value $=0.05 / 5=0.01$ for omnidirectional and row global neighbor tests per vineyard per neighbor order. 
mature vines. These fungi are present on protected surfaces inside cracks on cordons, trunks, and spurs, and in the old vascular tissues of pruning wounds (Edwards and Pascoe 2001; Edwards et al. 2001; Larignon and Dubos 2000). Local favorable microclimatic conditions within the vineyard could promote spore production, local spread, and infection by these fungi. This would consequently increase the number of esca cases in certain areas, forming a cluster. Exogenous inoculum from an environment close to the vineyard may also result in esca vine clustering at the edge of the vineyard.

The aggregated structures of symptomatic vines can also be explained by the heterogeneity of the structure and/or composition of the soil within the vineyard. First, the spatial heterogeneity of abiotic factors, such as levels of nutrients available for the plant, can explain the nonrandom distribution of symptomatic plants and the presence of clusters. Calzarano et al. (2009) showed differences in the incidence of leaf symptoms attributable to fertilizer applications and rainfall, suggesting that the greater availability of nutrients increased the proportion in diseased vines with esca symptoms. The heterogeneous structure of the soil can also lead to variability among vines of the same plot for their morphological features connected to water transport. Tramontini et al. (2013) showed that the morphometric characteristics of the xylem are influenced by soil. In a soil with a high availability of water, the vessel size was large. Pouzoulet et al. (2014) also provided evidence of cultivar susceptibility being correlated with larger vessel diameters. Further studies are needed to test the relationship between soil spatial heterogeneity and esca distribution over time within the four vineyards that showed aggregated patterns. Relevant technology is available to assess the spatial and temporal variability in soil environments on a field scale (Celano et al. 2011).

This study highlighted the large differences in the rate of disease and its progress over time among the plots. The temporal progress of esca prevalence by calendar year from 2004 could be empirically approximated by linear temporal curves for the majority of vineyards. These results agreed with those of Marchi et al. (2006) in Italy, and Reisenzein et al. (2000) in Austria. The authors observed a constant increase in prevalence over time for surveys of mature vines. In vineyards with the highest prevalence, a decreasing rate of disease progress over the last three years was observed, probably because fewer asymptomatic vines were available for foliar symptom expression. Because data recording only began when the vines were between 14 and 19 years of age, and the initial temporal disease pattern was unknown, we need to consider the relative prevalence values. Previously symptomatic plants could have been pruned, removed, or even have died, in 2004, when recording started. A better estimation might have been obtained by considering the dead, missing and newly planted vines if vine mortality had only been caused by esca, but the causes of mortality were not available.

Despite the vines being the same cultivar, Cabernet Sauvignon, of similar ages, and in the same region, our study showed strong contrasting levels of esca prevalence among vineyards which could potentially be explained by multiple variables, such as local climatic factors, the level of primary infection, the external sources of inocula, and the clonal and rootstock genetics associated with viticultural practices. The choice of grapevine material, even for the same cultivar, such as the type of clone or the rootstock variety, might influence the vine's vulnerability to GTDs. Our study revealed that the highest prevalence of esca within vineyards occurred with the rootstock 3309 C, described by Galet (1988) as being poorly adapted to drought. This observation corroborated those of Murolo and Romanazzi (2014), who found higher esca incidence levels on Fiano and Sauvignon when these were grafted onto rootstock SO4 rather than onto 1103P. They ascribed their results to the higher drought resistance of $1103 \mathrm{P}$ compared with SO4. Additional research is needed to better understand the variability of disease spread among vineyards and, in particular, vineyards showing weak rates of esca increase should be analyzed. We need focused studies to identify the environmental and agronomic practices that reduce disease risk.
With regard to the statistical tests used in this study, we would like to emphasize two points. The first is the flexibility of the JC statistics, which enables us to study different questions by changing the definition of the neighborhood vine status, such as asymptomatic, symptomatic at least one time, and symptomatic for a current year, and by modifying the type of permutation. This statistical method may be applied to examine other hypothetical spread processes. For instance, the spatial dependence between dead and symptomatic vines could be studied via the hypothesis of dead vines being a source of available inoculum for new infections. The second point is the hierarchical approach for hypotheses testing. This allowed us to select vineyards showing significant GD values and to focus on them to describe the spatial pattern of esca. These methods also reduced the procedures involved in multiple testing.

Using data from a large number of vineyards, recorded over a long period in the Bordeaux region, our results showed a weak, or no, capacity of esca spread at short distances along rows, which was not similar to those of Zanzotto et al. (2013). In their study, the temporal and spatial data for esca from a single vineyard were analyzed using Bayesian hierarchy models to identify spatial associations between symptomatic vines depending on the neighborhood structure of the disease. Their results suggested that secondary spread by rank exceeds the contribution of the random distribution of the inoculum and, therefore, concluded there was a role for cultural practices, such as the cuttings used, in secondary disease spread. In our current study, in some vineyards, we identified small clusters of two or three vines located along the rows, with no increase of their size over time. The presence of these microclusters can be related to a weak capacity for local transmission through the short-distance spread of pathogenic fungi from one vine to another (Table 1) or to similar locally conducive environmental conditions along the rows, as indicated above. Consequently, we conclude that contaminated pruning shears play a limited role in the spread of esca over time. However, by taking into account the disease temporal progress, which is rapid in some vineyards, we recommend that all of the practical measures aimed to limit the sources of inoculum and infection by the various pathogenic fungi associated with esca need to be followed. Moreover, all of the factors stressing vines should be reduced by adapting these measures to the agronomic and economic context of the vineyard. Further research should be focused on the identification of environmental key factors that explain esca aggregation at vineyard scale. Knowledge of the spatial heterogeneity factors (i.e., soil) should help to identify risk areas within vineyards. Agricultural precision technology could be used to locate these areas and specific control strategies could be applied to prevent esca spread.

\section{ACKNOWLEDGMENTS}

We thank all the vine-growers who participated in this study, and $\mathrm{S}$. Bastien for her excellent technical assistance; Professor $\mathrm{X}$. Xu (East Malling Research, UK) for a critical review of a preliminary version of the manuscript; and R. Godfrey for his kind assistance in improving the English of the manuscript. This study was funded by Bordeaux Sciences Agro, the Regional Council of Aquitaine, the JEAN POUPELAIN Foundation, the French Ministry of Agriculture and the Food-Processing Industry and Forest (CASDAR V907).

\section{LITERATURE CITED}

Agusti-Brisach, C., Garcia-Jimenez, L. M., and Armangol, J. 2015. Detection of grapevine fungal trunk pathogens on pruning shears and evaluation of their potential for spread infection. Plant Dis. 99:976-981.

Bertsch, C., Ramirez-Suero, M., Magnin-Robert, M., Larignon, P., Chong, J., Abou-Mansour, E., Spagnolo, A., Clément, C., and Fontaine, F. 2013. Grapevine trunk diseases: Complex and still poorly understood. Plant Pathol. 62:243-265.

Bland, J. M., and Altman, D. G. 1995. Multiple significance tests: The Bonferroni method. Br. Med. J. (Clin. Res. Ed.) 310:170.

Bruez, E., Lecomte, P., Grosman, J., Doublet, B., Bertsch, C., Fontaine, F., Udaglia, A., Teissedre, P. L., Da Costa, J. P., Guérin-Dubrana, L., and Rey, 
P. 2013. Overview of grapevine trunk diseases in France in the 2000s. Phytopathol. Mediterr. 52:262-275.

Calzarano, F., Amalfitano, C., Seghetti, L., and Cozzolino, V. 2009. Nutritional status of vines affected with esca proper. Phytopathol. Mediterr. 48:20-31.

Celano, G., Palese, A. M., Ciucci, A., Martorella, E., Vignozzi, N., and Xiloyannis, C. 2011. Evaluation of soil water in tilled and cover-cropped olive orchard by the geoelectrical technique. Geoderma 163:163-170.

Cortesi, P., Fischer, M., and Milgroom, M. G. 2000. Identification and spread of Fomitiporia punctata associated with wood decay of grapevine showing symptoms of esca. Phytopathology 90:967-972.

Edwards, J., Marchi, G., and Pascoe, I. G. 2001. Young esca in Australia. Phytopathol. Mediterr. 40:303-310.

Edwards, J., and Pascoe, I. G. 2001. Pycnidial state of Phaeomoniella chlamydospora found on Pinot noir grapevines in the field. Austral. Plant Pathol. 30:67.

Eskalen, A., and Gubler, W. D. 2001. Associated of spores of Phaeomoniella chlamydospora, Phaeoacremonium inflatipes, and $\mathrm{Pm}$ aleophilum with grapevine cordons in California. Phytopathol. Mediterr. 40:429-432.

Fischer, M. 2002. A new wood-decaying basidiomycete species associated with esca of grapevine: Fomitiporia mediterranea (Hymenochaetales). Mycol. Prog. $1: 315-324$.

Fussler, L., Kobes, N., Bertrand, F., Maumy, M., Grosman, J., and Savary, S. 2008. A characterization of grapevine trunk diseases in France from data generated by the National Grapevine Wood Diseases Survey. Phytopathology 98:571-579.

Galet, P. 1988. Cépages et vignobles de France. 2nd Ed. Tome 1 Les Vignes Américaines. P. Galet, France.

Gramaje, D., and Armengol, J. 2011. Fungal trunk pathogens in the grapevine propagation process: Potential inoculum sources, detection, identification and management strategies. Plant Dis. 95:1040-1055.

Gray, S. M., Moyer, J. W., and Bloomfield, P. 1986. Two dimensional distance class model for quantitative description of virus-infected plant distribution lattices. Phytopathology 76:243-248.

Larignon, P., and Dubos, B. 1997. Fungi associated with esca disease in grapevine. Eur. J. Plant Pathol. 103:147-157.

Larignon, P., and Dubos, B. 2000. Preliminary studies on the biology of Phaeoacremonium. Phytopathol. Mediterr. 39:184-189.

Larignon, P., Fulchic, R., Ceré, L., and Dubos, B. 2001. Observation on black dead arm in French vineyards. Phytopathol. Mediterr. 40:336-342.

Lecomte, P., Darrieutort, G., Laveau, C., Blancard, D., Louvet, G., Goutouly, J. P., Rey, P., and Guérin-Dubrana, L. 2011. Impact of biotic and abiotic factors on the development of esca decline disease. Integrated protection and production in viticulture. IOBC WPRS Bull. 67:171-180.

Lecomte, P., Darrieutort, G., Liminana, J.-M., Comont, G., Muruamendiaraz, A., Legorburu, F.-J., Choueiri, E., Jreijiri, F., El Amil, R., and Fermaud, M. 2012. New insights into esca of grapevine: The development of foliar symptoms and their association with xylem discoloration. Plant Dis. 96:924-934.

Madden, L. V., Hughes, G., and van den Bosch, F. 2007. The Study of Plant Disease Epidemics. The American Phytopathological Society, St Paul, MN.

Marchi, G., Peduto, F., Mugnai, L., Di Marco, S., Calzarano, F., and Surico, G. 2006. Some observations on the relationship of manifest and hidden esca to rainfall. Phytopathol. Mediterr. 45:117-126.

Moran, P. A. 1948. The interpretation of statistical maps. J. Roy. Stat. Soc. Ser. B. Stat. Methodol. 10:243-251.

Mostert, L., Groenwald, J. Z., Summerbell, R. C., Robert, V., Sutton, D. A., Padhye, A. A., and Crous, P. W. 2005. Species of Phaeoacremonium associated with human infections and environmental reservoirs in infected woody plants. J. Clin. Microbiol. 43:1752-1767.

Moyo, P., Allsopp, E., Roets, F., Mostert, L., and Halleen, F. 2014. Arthropods vector grapevine trunk disease pathogens. Phytopathology 104:1063-1069.

Mugnai, L., Graniti, A., and Surico, G. 1999. Esca (black measles) and brown wood-streaking: Two old and elusive diseases of grapevines. Plant Dis. 83: 404-418.

Murolo, S., and Romanazzi, G. 2014. Effects of grapevine cultivar, rootstock and clone on esca disease. Australas. Plant Pathol. 43:215-221.

Pethybridge, S. J., and Madden, L. V. 2003. Analysis of spatiotemporal dynamics of virus spread in an Australian hop garden by stochastic modelling. Plant Dis. 87:56-62.

Phipson, B., and Smyth, G. K. 2010. Permutation $P$ values should never be zero: Calculating exact $P$ values when permutations are randomly drawn. Stat. Appl. Genet. Mol. Biol. 9:1-16.

Pollastro, S., Dongiovanni, C., Habib, W., and Faretra, F. 2009. Long-term observations on the spatial distribution of esca disease in vineyards. J. Plant Pathol. 91:80.

Pouzoulet, J., Pivovaroff, A. L., Santiago, L. S., and Rolshausen, P. E. 2014. Can vessel dimension explain tolerance toward fungal vascular wilt diseases in woody plants? Lessons from Dutch elm disease and esca disease in grapevine. Front. Plant Sci. 5:253.

R Development Core Team. 2013. R: A Language and Environment for Statistical Computing. Vienna, Austria. http://www.r-project.org/

Redondo, C., Avila, A., Mateo-Sagasta, E., and Tello, M. L. 2001. Spatial distribution of symptomatic grapevines with esca disease in the Madrid region (Spain). Phytopathol. Mediterr. 40:439-442.

Reisenzein, H., Berger, N., and Nieder, G. 2000. Esca in Austria. Phytopathol. Mediterr. 39:26-34.

Sofia, J., Gonçalves, M. T., and Oliveira, H. 2006. Spatial distribution of esca symptomatic plants in Dao vineyards (Centre Portugal) and isolation of associated fungi. Phytopathol. Mediterr. 45:87-92.

Stefanini, F. M., Surico, G., and Marchi, G. 2000. Longitudinal analysis of symptom expression in grapevines affected by esca. Phytopathol. Mediterr. 39:225-231.

Surico, G., Marchi, G., Ferrandino, F. J., Braccini, P., and Mugnai, L. 2000. Analysis of the spatial spread of esca in some Tuscan vineyards (Italy). Phytopathol. Mediterr. 39:211-224.

Surico, G., Mugnai, L., and Marchi, G. 2008. The esca disease complex. Pages 119-136 in: Integrated management of diseases caused by fungi, phytoplasma and bacteria. A. Ciancio and K. G. Mukerji, eds. Springer, The Netherlands.

Thébaud, G., Peyrard, N., Dallot, S., Calonnec, A., and Labonne, G. 2005. Investigating disease spread between two assessments with permutation tests on a lattice. Phytopathology 95:1453-1461.

Tramontini, S., van Leeuwen, C., Domec, J. C., Destrac-Irvine, A., Basteau, C., Vitali, M., Mosbach-Schulz, O., and Lovisolo, C. 2013. Impact of soil texture and water availability on the hydraulic control of plant and grape-berry development. Plant Soil 368:215-230.

White, C. L., Halleen, F., and Mostert, L. 2011. Symptoms and fungi associated with esca in South African vineyards. Phytopathol. Mediterr. 50:236-246.

Zanzotto, A., Gardiman, M., Serra, S., Bellotto, D., Bruno, F., Greco, F., and Trivisano, C. 2013. The spatiotemporal spread of esca disease in a Cabernet Sauvignon vineyard: A statistical analysis of field data. Plant Pathol. 62: 1205-1213. 